\title{
Clinical phenotypes of Korean patients with Behcet disease according to gender, age at onset, and HLA-B 51
}

Hee Jung Ryu, Mi Ryoung Seo, Hyo Jin Choi, and Han Joo Baek

Department of Rheumatology, Gachon University Gil Medical Center, Incheon, Korea

\author{
Received: May 26, 2016 \\ Revised : September 28, 2016 \\ Accepted: October 23, 2016

\section{Correspondence to} \\ Han Joo Baek, M.D. \\ Department of Rheumatology, \\ Gachon University Gil Medi- \\ cal Center, 21 Namdong-daero \\ 774beon-gil, Namdong-gu, \\ Incheon 21565 , Korea \\ Tel: $+82-32-460-8426$ \\ Fax: $+82-32-460-8410$ \\ E-mail: baekhj@gilhospital.com
}

Background/Aims: The clinical manifestations of Behcet disease (BD) have been reported to differ according to country, region, and race. Gender, onset age, and human leukocyte antigen (HLA)-B51 have also been known as the factors that influence the clinical features of BD. The aim of this study is to investigate the clinical phenotypes of Korean patients who visited the rheumatology clinic with $\mathrm{BD}$ with respect to gender, onset age, and HLA-B51.

Methods: Total 193 Korean patients (129 females and 64 males) fulfilling the international criteria for BD were retrospectively assessed.

Results: The mean age at disease onset and disease duration of the BD patients were $32.2 \pm 11.1$ and $14.2 \pm 9.3$ years, retrospectively. Females suffered more frequently from genital ulcers (90.7\% vs. $75.0 \%, p<0.01)$, peripheral arthritis $(67.4 \%$ vs. $43.8 \%, p<0.01)$, and inflammatory low back pain ( $38.8 \%$ vs. $23.4 \%, p=0.03$ ) than males, while skin involvement was more frequent in males than in females (90.6\% vs. $75.2 \%, p=0.01$ ). The patients with late onset of $\mathrm{BD}(>40$ years) suffered from neurologic involvement ( $15.9 \%$ vs. $4.2 \%, p=0.007$ ) more frequently than those with early onset of BD. The patients with HLA-B51 showed earlier onset of disease than without HLA-B $51(28.3 \pm 11.4$ years vs. $33.8 \pm 11.6$ years, $p=0.02)$ and the neurologic and gastrointestinal involvements were more frequent in the patients without HLA-B 51 than with HLA-B 51 (17.2\% vs. $2.5 \%, p=0.02$ and $20.7 \%$ vs. $2.5 \%, p=0.01$, respectively).

Conclusions: The clinical phenotypes in Korean patients with BD may be influenced by gender, onset age and HLA-B51.

Keywords: Behcet syndrome; Gender identity; Age of onset; HLA-B51 antigen

\section{INTRODUCTION}

Behcet disease $(\mathrm{BD})$ is a chronic inflammatory disease that has recurrent oral and genital ulcers as a prominent feature, but can involve almost all organs, including the skin, eyes, gastrointestinal tract, joints, cardiovascular system, and nervous system [1]. Although the prevalence is highest in East Asian countries, the Middle East and the Eastern Mediterranean area, BD can be found in any country due to immigration $[2,3]$.

The etiology of $\mathrm{BD}$ is uncertain, but genetic such as human leukocyte antigen (HLA)-B51, environmental, microbiological and immunological factors have been proposed to be related with $\mathrm{BD}$ [4]. According to the country, clinical manifestations have been reported to differ according to country, region, and race [5-7]. Oc- 
ular manifestations develop in $35 \%$ to $92 \%$ of cases and gastrointestinal manifestations in $3.3 \%$ to $37 \%$, and central nervous system involvement occurs in o\% to $44 \%$ of cases [5]. In Israel, Arab patients have more severe eye disease than Jewish patients and the Druse have milder ocular and neurologic involvement than Arabs [6,7]. Demographic factors including gender [8-12] and age at onset [13-19] or genetic factors such as HLA-B51 [20-23] have also been reported to influence the clinical manifestations of $\mathrm{BD}$. However, the reported results varied countries, regions, and races [8-23]. Thus we assume that multiple factors including race, region, country, gender, and genetics could influence clinical manifestations in a complex manner.

There were not many studies about the influence of demographic and genetic factors on clinical phenotypes of BD although they used different diagnostic criteria. Especially, Korean data on the basis of rheumatology clinics were lacking. The aim of this study is to investigate the clinical phenotypes of Korean patients who visited the rheumatology clinic with $\mathrm{BD}$ according to demographic and genetic factors. To do this we selected gender, age at onset, and HLA-B51 status as influence factors that were suggested by previous reports.

\section{METHODS}

We retrospectively reviewed the medical records of 193 BD patients who consecutively visited our rheumatology clinic. All of them fulfilled the international criteria for BD (ICBD) [24]. The study protocol was approved by Institutional Review Board of Gachon University Gil Medical Center and informed consent was waived from all patients by the Board (GCIRB2971-2012).

Clinical and laboratory findings were obtained from the medical records. Ocular lesions were diagnosed by the ophthalmologist. We defined joint involvement as joint swelling or pain with swelling of the joint or articular damage on simple radiography. Inflammatory back pain (IBP) was evaluated according to the criteria of Assessment of SpondyloArthritis international Society (ASAS) experts [25]. Vascular manifestations included venous thrombophlebitis, arteritis and superficial phlebitis that were confirmed by Doppler sonography or angiography. Neurologic involvement (Neuro-BD) was diagnosed by international consensus recommendation criteria for Neuro-BD diagnosis and included the definite neuro-BD and the probable neuro-BD [26]. Gastrointestinal involvement was defined as confirmed with gastroduodenoscopy or colonoscopy by gastroenterologists.

We defined the onset of $\mathrm{BD}$ as the age of the patient when the initial manifestation of BD presented. The duration of $\mathrm{BD}$ was calculated as the time interval between the onset of $\mathrm{BD}$ and the age at the last visit of the patient to our clinic. Onset age could be informed from 188 patients and HLA-B51 was tested for in 98 patients. Major organ involvement was defined as involvement of the eyes, nervous system, gastrointestinal tract or vessels.

The comparisons of the clinical manifestations according to gender, onset age, and HLA-B51 status were performed using the chi-square test, Fisher exact test, or Student $t$ test. Statistical calculations were conducted using SPSS version 17.0 (SPSS Inc., Chicago, IL, USA). A value of $p<0.05$ was considered to indicate statistical significance.

\section{RESULTS}

Of the 193 BD patients, 129 (66.8\%) were female and 64 (33.2\%) were male. The male to female ratio was 0.5:1. The mean ages $( \pm \mathrm{SD})$ at disease onset and at enrollment of patients with BD were $32.2 \pm 11.1$ and $44.7 \pm 11.1$ years, respectively. The mean disease duration of BD was 14.2 \pm 9.3 years (Table 1).

The oral ulcer was the most common manifestation, followed by genital ulcers, skin involvement, peripheral arthritis, major organ involvement, and IBP (Table 1). The number of patients with major organ involvement increased over time. In 32 patients (16.6\%), BD presented with major organ involvement; uveitis (13\%), gastrointestinal involvement (5.2\%), vascular involvement (3.1\%), and neurologic involvement (1\%). And total 76 patients (39.4\%) experienced the major organ involvements for their disease duration. The frequencies of all types of major organ involvement, with the exception of vascular involvement, increased more than 2-fold during the course of BD compared to the onset of BD. Thirty-one of $105 \mathrm{BD}$ patients (29.5\%) who were performed the pathergy test showed positive reaction. HLA-B51 was present in 40 of 98 patients (40.8\%). 
Table 1. Clinical manifestations of Behcet disease according to gender

\begin{tabular}{|c|c|c|c|c|}
\hline Clinical feature & Total $(\mathrm{n}=193)$ & Female $(\mathrm{n}=129)$ & Male $(n=64)$ & $p$ value \\
\hline Age, yr & $44.7 \pm 11.1$ & $44.6 \pm 10.4$ & $44.7 \pm 12.5$ & NS \\
\hline Onset age, yr & $32.2 \pm 11.1$ & $31.5 \pm 10.7$ & $33.8 \pm 11.8$ & NS \\
\hline Disease duration, yr & $14.2 \pm 9 \cdot 3$ & $15.0 \pm 9.8$ & $12.4 \pm 7.9$ & NS \\
\hline Follow-up duration, yr & $4.7 \pm 3.8$ & $4 \cdot 5 \pm 3 \cdot 6$ & $5 \cdot 1 \pm 4 \cdot 0$ & NS \\
\hline Positive HLA-B51 (performed in 98 patients) & $40(40.8)$ & $28(43.1)$ & $12(36.4)$ & NS \\
\hline Positive pathergy test (performed in 105 patients) & $31(29 \cdot 5)$ & $18(25 \cdot 7)$ & $13(37 \cdot 1)$ & NS \\
\hline Oral ulcer & $191(99.0)$ & $127(98.4)$ & $64(100.0)$ & NS \\
\hline Genital ulcer & $165(85 \cdot 5)$ & $117(90.7)$ & $48(75.0)$ & $<0.01$ \\
\hline Skin lesion & $155(80.3)$ & $97(75 \cdot 2)$ & $58(90.6)$ & 0.01 \\
\hline Pseudofolliculitis & $87(45 \cdot 1)$ & $50(38.8)$ & $37(57.8)$ & 0.01 \\
\hline Erythema nodosum & $102(52.8)$ & $64(49.6)$ & $38(59 \cdot 4)$ & NS \\
\hline Joint involvements & $122(63.2)$ & $91(70.5)$ & $31(48.4)$ & $<0.01$ \\
\hline Arm & $71(33.0)$ & $56(43 \cdot 4)$ & $15(23 \cdot 4)$ & $<0.01$ \\
\hline Leg & $90(46.6)$ & $65(50.4)$ & $25(39.1)$ & NS \\
\hline Shoulder & $21(10.9)$ & $18(14.0)$ & $3(4 \cdot 7)$ & NS \\
\hline Hip & $6(3.1)$ & $5(3.9)$ & $1(1.6)$ & NS \\
\hline Inflammatory back pain & $65(33.7)$ & $50(38.8)$ & $15(23 \cdot 4)$ & 0.03 \\
\hline Major organ involvement & $76(39.4)$ & $49(38.0)$ & $27\left(4^{2.2}\right)$ & NS \\
\hline Uveitis & $52(26.9)$ & $31(24.0)$ & $21(32.8)$ & NS \\
\hline Neurologic & $13(6.7)$ & $8(6.2)$ & $5(7.8)$ & NS \\
\hline Gastrointestinal & $22(11.4)$ & $16(12.4)$ & $6(9.4)$ & NS \\
\hline Vascular & $8(4.1)$ & $3(2.3)$ & $5(7.8)$ & NS \\
\hline
\end{tabular}

Values are presented as mean \pm SD or number (\%).

NS, not significant; HLA, human leukocyte antigen.

\section{Clinical manifestations according to gender}

The mean age at onset and the mean disease duration were not different according to gender. And HLA-B51 status and the positivity of pathergy test were similar in both genders. Genital ulcers, peripheral joint involvement, and IBP were more common in females, while skin lesions were more frequent in males. The differences in the frequencies of major organ involvements between genders were not statistically significant (Table 1 ).

\section{Clinical manifestations according to age at onset}

There were no differences of clinical features according to age at onset except neurologic involvement (Table 2).

\section{Clinical manifestations according to the status of HLA-B51}

The patients with HLA-B51 showed significantly earli- er onset than without HLA-B51. Pseudofolliculitis was more frequent in the patients with HLA-B51, while major organ, including gastrointestinal and neurologic, involvements were more prevalent in the patients without HLA-B51 than with HLA-B51 (Table 3).

\section{DISCUSSION}

There are limited data about the influences of gender, age at onset, and HLA-B51 on the clinical manifestations of BD. They have been differently reported among countries and regions. It may be attributed to the variable diagnostic criteria for $\mathrm{BD}$ that were applied, as well as racial and national differences. Oral ulcer is an obligatory manifestation for BD diagnosis by the diagnostic criteria of the International Study Group (ISG) [27], 
Table 2. Clinical manifestations of Behcet disease according to onset of age

\begin{tabular}{|c|c|c|c|c|}
\hline Clinical feature & $\operatorname{Total}(\mathrm{n}=188)$ & $\leq 40$ Years $(n=144)$ & $>40$ Years $(n=44)$ & $p$ value \\
\hline Age, yr & $44.6 \pm 10.9$ & $40.9 \pm 9.0$ & $56.7 \pm 7.4$ & $<0.00$ \\
\hline Onset age, yr & $32.2 \pm 11.1$ & $27.7 \pm 7.8$ & $47.2 \pm 6.0$ & $<0.00$ \\
\hline Disease duration, yr & $14.2 \pm 9.3$ & $14.9 \pm 9.6$ & $11.8 \pm 7.9$ & NS \\
\hline Follow-up duration, yr & $4.7 \pm 3 \cdot 7$ & $4 \cdot 3 \pm 3 \cdot 6$ & $5 \cdot 9 \pm 3 \cdot 9$ & 0.01 \\
\hline Positive HLA-B51 (performed in 96 patients) & $39(40.6)$ & $32(45 \cdot 1)$ & $7(28.0)$ & NS \\
\hline Positive pathergy test (performed in 103 patients) & $30(29.1)$ & $23(28.0)$ & $7(33 \cdot 3)$ & NS \\
\hline Oral ulcer & $186(98.9)$ & $143(99 \cdot 3)$ & $43(97.7)$ & NS \\
\hline Genital ulcer & $160(85.1)$ & $125(86.8)$ & $35(79.5)$ & NS \\
\hline Skin lesion & $151(80.3)$ & $117(81.3)$ & $34(77 \cdot 3)$ & NS \\
\hline Pseudofolliculitis & $85(45 \cdot 2)$ & $67(46.5)$ & $18(40.9)$ & NS \\
\hline Erythema nodosum & $99(52.7)$ & $78(54.2)$ & $21(47 \cdot 7)$ & NS \\
\hline Joint involvements & $120(63.8)$ & $93(64.6)$ & $27(61.4)$ & NS \\
\hline Arm & $69(36.7)$ & $56(38.9)$ & $13(29 \cdot 5)$ & NS \\
\hline Leg & $88(46.8)$ & $69(47 \cdot 9)$ & $19(43.2)$ & NS \\
\hline Shoulder & $21(11.2)$ & $18(12.5)$ & $3(6.8)$ & NS \\
\hline Hip & $6(3.2)$ & $3(2.1)$ & $3(6.8)$ & NS \\
\hline Inflammatory back pain & $64(34.0)$ & $49(34.0)$ & $15(34.1)$ & NS \\
\hline Major organ involvement & $75(39.9)$ & $55(38.2)$ & $20(45 \cdot 5)$ & NS \\
\hline Uveitis & $52(27.7)$ & $40(27.8)$ & $12(27 \cdot 3)$ & NS \\
\hline Neurologic & $11(11.2)$ & $6(4.2)$ & $7(15 \cdot 9)$ & 0.007 \\
\hline Gastrointestinal & $21(11.2)$ & $14(9.7)$ & $7(15 \cdot 9)$ & NS \\
\hline Vascular & $8(4 \cdot 3)$ & $5(3 \cdot 5)$ & $3(6.8)$ & NS \\
\hline
\end{tabular}

Values are presented as mean $\pm \mathrm{SD}$ or number (\%).

NS, not significant; HLA, human leukocyte antigen.

which can exclude BD patients without oral ulcers. The diagnostic criteria of the Research Committee of Japan (RCJ) place great emphasis on ocular involvement [28], although it may include patients with ocular lesions associated with other diseases such as spondyloarthritis. The sensitivity and specificity of the criteria for BD have been reported to be $79.8 \%$ and $98.3 \%$ by ISG criteria, $85.3 \%$ and $97.1 \%$ by RCJ criteria and $70.7 \%$ and $97.6 \%$ by O'Duffy's criteria, respectively [29]. ICBD was recently developed and showed increased sensitivity and accuracy by $20.1 \%$ and $11.8 \%$, respectively compared with ISG criteria [30]. We studied the patients with $\mathrm{BD}$ who visited the rheumatology clinic and met the ICBD criteria. While majority of previous studies were analyzed by a specific single parameter, we investigated the comprehensive effects of multiple factors including gender, age at onset, and HLA-B51 on the clinical phenotypes of BD.
In contrast to a previous Korean study showing that skin disease was dominant in females and uveitis was dominant in males [8], we found that skin disease was dominant in males and the frequency of uveitis was not different in both genders. These differing results could be explained by the different diagnostic criteria of BD as the previous study used ISG or RCJ criteria and our study did ICBD. Moreover there could be the difference of patients' characteristics according to the clinic where these studies were performed (dermatologic clinic in the previous study vs. rheumatologic clinic in our study). Actually the previous Korean study that performed in dermatologic clinic showed lesser frequent involvements of internal organs (gastrointestinal involvement 3.2\%, neurologic involvement 1.5\%, and vascular involvement 1.7\%) compared with our study [8]. Our data on the basis of rheumatology clinic could encompass BD patients 
Table 3. Clinical manifestations of Behcet disease according to HAL-B 51 positivity

\begin{tabular}{|c|c|c|c|c|}
\hline Clinical feature & $\operatorname{Total}(n=98)$ & Positive HLA-B51 $(n=40)$ & Negative HLA-B $51(n=58)$ & $p$ value \\
\hline Age, yr & $44.8 \pm 10.9$ & $43.4 \pm 10.5$ & $45 \cdot 9 \pm 11.1$ & NS \\
\hline Onset age, yr & $31.6 \pm 11.8$ & $28.3 \pm 11.4$ & $33.8 \pm 11.6$ & 0.02 \\
\hline Disease duration, yr & $13.7 \pm 9.0$ & $16.0 \pm 10.5$ & $12.1 \pm 7.6$ & 0.04 \\
\hline Follow-up duration, yr & $4.8 \pm 3.2$ & $4.3 \pm 3.2$ & $5.1 \pm 3.3$ & NS \\
\hline $\begin{array}{l}\text { Positive pathergy test } \\
\text { (performed in } 66 \text { patients) }\end{array}$ & $19(28.8)$ & $8(28.6)$ & $11(16.7)$ & NS \\
\hline Oral ulcer & $96(98.0)$ & $40(100.0)$ & $56(96.6)$ & NS \\
\hline Genital ulcer & $80(81.6)$ & $33(82.5)$ & $47(81.0)$ & NS \\
\hline Skin lesion & $85(86.7)$ & $36(90.0)$ & $49(84.5)$ & NS \\
\hline Pseudofolliculitis & $44(44.9)$ & $23(57.5)$ & $21(36.2)$ & 0.04 \\
\hline Erythema nodosum & $53(54.1)$ & $18(45.0)$ & $35(60.3)$ & NS \\
\hline Joint involvements & $52(53.1)$ & $19(47.5)$ & $33(56.9)$ & NS \\
\hline Arm & $32(32.7)$ & $12(30.0)$ & $20(34.5)$ & NS \\
\hline Leg & $36(36.7)$ & $13(32.5)$ & $23(39 \cdot 7)$ & NS \\
\hline Shoulder & $11(11.2)$ & $2(5.0)$ & $9(15.5)$ & NS \\
\hline Hip & $2(2.0)$ & o & $2(3.4)$ & NS \\
\hline Inflammatory back pain & $22(22.4)$ & $6(15.0)$ & $16(29.6)$ & NS \\
\hline Major organ involvement & $41(41.8)$ & $11(27.5)$ & $30(51.7)$ & 0.02 \\
\hline Uveitis & $25(25.5)$ & $9(22.5)$ & $16(27.6)$ & NS \\
\hline Neurologic & $11(11.2)$ & $1(2.5)$ & $10(17.2)$ & 0.02 \\
\hline Gastrointestinal & $13(13 \cdot 3)$ & $1(2.5)$ & $12(20.7)$ & 0.01 \\
\hline Vascular & $7(7.1)$ & $1(2.5)$ & $6(10.7)$ & NS \\
\hline
\end{tabular}

Values are presented as mean \pm SD or number (\%).

HLA, human leukocyte antigen; NS, not significant.

with much more diverse clinical features compared the dermatology clinic.

Females with BD more commonly had arthritis and genital ulcers than males in our study and other previous results $[8,12,31]$. Interesting, although IBP is still uncertain as occurring as a clinical feature of $\mathrm{BD}$, it presented in $33.7 \%$ of our patients, especially in female patients. So far several case reports have suggested the possible coexistence of BD and ankylosing spondylitis (AS) [32,33]. Our series did not include AS patients and IBP seemed to be associated with BD. Further studies will be required on the axial joint involvement in $\mathrm{BD}$. Previous studies reported that vascular and ocular involvement was observed more frequently in males [10-11,17]. However, our study showed no differences in major organ involvements between genders, although uveitis was observed more frequently in males only at the onset of BD.
To evaluate the effect of age at disease onset on BD clinical features, we divided the patients into two groups based on the reference age of 40 that was suggested by a previous study $[17]$. This age could reflect the point when the levels of sex hormones changed abruptly. Some previous studies have reported the possible influence of sex hormones such as testosterone and androgen on BD [34,35]. In our study, neurologic involvement was more frequent in $\mathrm{BD}$ patients with late onset than those with early onset. From Turkish studies, it was reported that genital ulcers and ocular involvement were more frequent in patients with early onset ( $<40$ years) [17]. Male patients with younger onset $(\leq 25$ years) had more frequent major organ involvement with immunosuppressive use [18]. This different clinical features according to the age at onset might influenced by change of sex hormone such as testosterone and prolactin [34-36]. 
HLA-B51, known to be linked the risk of BD, may influence the clinical features in BD patients. Our BD patients with HLA-B51 showed earlier onset, more pseudofolliculitis and less gastrointestinal and neurologic involvements, which is comparable to previous reports. On the contrary, an earlier study on Korean 61 patients with BD showed that the patients with HLA-B 51 suffered with more frequent uveitis and erythema nordosum and suggested HLA-B51 might be a genetic marker of the severe disease as related with uveitis and complete $\mathrm{BD}[22]$. These contrasting results of the earlier Korean study may be caused by the diagnostic criteria of BD differed from us. The previous study used RCJ criteria and $16 \%$ of enrolled patients satisfied the criteria of complete $\mathrm{BD}$. Thus the patients with full-blown BD could be enrolled much more in the previous study. Another study from Tunisian patients revealed that HLA-B51 was associated with a lower frequency of arterial aneurysm and neurological involvement although it was related with high frequency of eye involvement [23]. A meta-analysis of the relationship between HLA-B51/ $\mathrm{B}_{5}$ and clinical manifestations in BD, HLA-B51/B5 was associated with moderately higher prevalence of eye involvement and lower prevalence of gastrointestinal involvement [21].

In conclusion, our study suggested that BD has the different clinical phenotypes according to gender, age at onset, and HLA-B51 status. Age at onset and HLA-B51 status may influence on the major organ involvements. Further investigation will be required on the influences of these factors on the clinical course and prognosis of BD patients.

\section{KEY MESSAGE}

1. Behcet disease (BD) has the different clinical phenotypes according to gender, age at onset and human leukocyte antigen (HLA)-B51 status.

2. In BD, age at onset HLA-B51 status may influence on the major organ involvements.

\section{Conflict of interest}

No potential conflict of interest relevant to this article was reported.

\section{Acknowledgments}

This study was supported by the Gachon University Gil Medical Center (grant number: 2013-03).

\section{REFERENCES}

1. Davatchi F, Shahram F, Chams C, Chams H, Nadji A. Behcet's disease. Acta Med Iran 2005;43:233-242.

2. Khairallah M, Accorinti M, Muccioli C, Kahloun R, Kempen JH. Epidemiology of Behcet disease. Ocul Immunol Inflamm 2012;20:324-335.

3. Kaklamani VG, Vaiopoulos G, Kaklamanis PG. Behcet's disease. Semin Arthritis Rheum 1998;27:197-217.

4. Onder M, Gurer MA. The multiple faces of Behcet's disease and its aetiological factors. J Eur Acad Dermatol Venereol 2001;15:126-136.

5. Davatchi F, Shahram F, Chams-Davatchi C, et al. Behcet's disease: from East to West. Clin Rheumatol 2010;29:823833 .

6. Krause I, Mader R, Sulkes J, et al. Behcet's disease in Israel: the influence of ethnic origin on disease expression and severity. J Rheumatol 2001;28:1033-1036.

7. Rozenbaum M, Boulman N, Slobodin G, et al. Behcet disease in adult Druzes in north Israel: the influence of ethnic origin on disease expression and severity. J Clin Rheumatol 2007;13:124-127.

8. Bang DS, Oh SH, Lee KH, Lee ES, Lee SN. Influence of sex on patients with Behcet's disease in Korea. J Korean Med Sci 2003;18:231-235.

9. Shang Y, Han S, Li J, Ren Q, Song F, Chen H. The clinical feature of Behcet's disease in Northeastern China. Yonsei Med J 2009;50:630-636.

10. Davatchi F, Shahram F, Chams C, et al. The influence of gender on the frequency of clinical symptoms in Behcet's disease. Adv Exp Med Biol 2003;528:65-66.

11. Tursen U, Gurler A, Boyvat A. Evaluation of clinical findings according to sex in 2313 Turkish patients with Behcet's disease. Int J Dermatol 2003;42:346-351.

12. Zouboulis CC, Vaiopoulos G, Marcomichelakis N, et al. Onset signs, clinical course, prognosis, treatment and outcome of adult patients with Adamantiades-Behcet's disease in Greece. Clin Exp Rheumatol 2003;21(4 Suppl 30):S19-S26.

13. Saricaoglu H, Karadogan SK, Bayazit N, Yucel A, Dilek K, Tunali S. Clinical features of late-onset Behcet's disease: 
report of nine cases. Int J Dermatol 2006;45:1284-1287.

14. Tsai J, Chen GS, Lu YW, Wu CS, Lan CC. Late-onset Behcet's disease does not correlate with indolent clinical course: report of seven Taiwanese patients. J Eur Acad Dermatol Venereol 2008;22:596-600.

15. Sungur G, Hazirolan D, Hekimoglu E, Kasim R, Duman S. Late-onset Behcet's disease: demographic, clinical, and ocular features. Graefes Arch Clin Exp Ophthalmol 2010;248:1325-1330.

16. Hazirolan D, Sungur G, Duman S. Demographic, clinical, and ocular features in patients with late-onset Behcet disease. Ocul Immunol Inflamm 2012;20:119-124.

17. Alpsoy E, Donmez L, Onder M, et al. Clinical features and natural course of Behcet's disease in 661 cases: a multicentre study. Br J Dermatol 2007;157:901-906.

18. Hamuryudan V, Hatemi G, Tascilar K, et al. Prognosis of Behcet's syndrome among men with mucocutaneous involvement at disease onset: long-term outcome of patients enrolled in a controlled trial. Rheumatology (Oxford) 2010;49:173-177.

19. Hamzaoui A, Jaziri F, Ben Salem T, et al. Comparison of clinical features of Behcet disease according to age in a Tunisian cohort. Acta Med Iran 2014;52:748-751.

20. Wallace GR. HLA-B ${ }^{\star} 51$ the primary risk in Behcet disease. Proc Natl Acad Sci U S A 2014;111:8706-8707.

21. Maldini C, Lavalley MP, Cheminant M, de Menthon M, Mahr A. Relationships of HLA-B51 or B5 genotype with Behcet's disease clinical characteristics: systematic review and meta-analyses of observational studies. Rheumatology (Oxford) 2012;51:887-900.

22. Chang HK, Kim JU, Cheon KS, Chung HR, Lee KW, Lee IH. HLA-B51 and its allelic types in association with Behcet's disease and recurrent aphthous stomatitis in Korea. Clin Exp Rheumatol 2001;19(5 Suppl 24):S31-S35.

23. Hamzaoui A, Houman MH, Massouadia M, et al. Contribution of Hla-B51 in the susceptibility and specific clinical features of Behcet's disease in Tunisian patients. Eur J Intern Med 2012;23:347-349.

24. International Team for the Revision of the International Criteria for Behcet's Disease (ITR-ICBD). The International Criteria for Behcet's Disease (ICBD): a collaborative study of 27 countries on the sensitivity and specificity of the new criteria. J Eur Acad Dermatol Venereol 2014;28:338-347.
25. Sieper J, van der Heijde D, Landewe R, et al. New criteria for inflammatory back pain in patients with chronic back pain: a real patient exercise by experts from the Assessment of SpondyloArthritis international Society (ASAS). Ann Rheum Dis 2009;68:784-788.

26. Kalra S, Silman A, Akman-Demir G, et al. Diagnosis and management of Neuro-Behcet's disease: international consensus recommendations. J Neurol 2014;261:16621676.

27. International Study Group for Behcet's Disease. Criteria for diagnosis of Behcet's disease. Lancet 1990;335:10781080.

28. Behcet's Disease Research Committee of Japan. Behcet's disease guide to the diagnosis of Behcet's disease (1972). Jpn J Ophthalmol 1974;18:291-294.

29. Davatchi F, Shahram F, Nadji A, et al. Performance of existing diagnosis/classification criteria for Behcet's disease in Iranian patients: analysis of 5666 patients and 2406 controls. APLAR J Rheum 2006;9:238-243.

30. Davatchi F, Sadeghi Abdollahi B, Shahram F, et al. Validation of the international criteria for Behcet's disease (ICBD) in Iran. Int J Rheum Dis 2010;13:55-6o.

31. Krause I, Yankevich A, Fraser A, et al. Prevalence and clinical aspects of Behcet's disease in the north of Israel. Clin Rheumatol 2007;26:555-560.

32. Kotevoglu N. Coexistence of ankylosing spondylitis and Behcet's disease: two cases with atypical presentation and course. Scand J Rheumatol 2003;32:184-185.

33. Cimen OB, Sahin G, Bicer A, Erdogan C. Behcet's syndrome coexisting with clinically occult ankylosing spondylitis. Z Rheumatol 2002;61:440-442.

34. Yavuz S, Ozilhan G, Elbir Y, Tolunay A, Eksioglu-Demiralp E, Direskeneli H. Activation of neutrophils by testosterone in Behcet's disease. Clin Exp Rheumatol 2007;25(4 Suppl 45):S46-S51.

35. Alpsoy E, Elpek GO, Yilmaz F, et al. Androgen receptor levels of oral and genital ulcers and skin pathergy test in patients with Behcet's disease. Dermatology 2005;210:3135 .

36. Atasoy M, Karatay S, Yildirim K, Kadi M, Erdem T, Senel $\mathrm{K}$. The relationship between serum prolactin levels and disease activity in patients with Behcet's disease. Cell Biochem Funct 2006;24:353-356. 